\title{
Di Çarçoveya Teoriya Performansê de Nirxandina Vegotinên Gelêrî
}

An Evaluation of Folk-narratives in the Frame of Performance Theory

\section{Necat Keskin ${ }^{1}$}

Received: January 4, 2015 Accepted: January 26, 2015

\begin{abstract}
Folk-Narratives such as folktales, myth, epos, legend are genres of the folk literature which is one of the main branch of folklore discipline. Those narratives have been transferred from generation to next one orally an anonymously for centuries. In the very beginning of the folklore discipline those genres have been evaluated as a text which mostly ignored their context and texture. In the 1970's discussing over evaluating them in their contextual performing began among folklorists. In this frame re-narrating of those folk narratives and even their exhibition begun to be subject of the works. In this article, some examples of turkish and kurdish folk narratives such as 'Uykudan önce (before sleeping)', 'Intangible Heritage Museum', "Dengbêj in the Dengbêj House', 'Mem û Zîn', and 'Pîrê û Rovî (a kurdish folktale)' have been dicussed and evaluated in the frame of performance theory which is one of the recent influential theories of folklore.
\end{abstract}

Keywords: Folk Narratives, Turkish, Kurdish, Performance Theory, Zarok tv.

\section{Özet}

Masal, mit, destan, efsane gibi halk anlatıları, folklor disiplinin bir ana dalı olarak halk edebiyatının türleridirler. Bu anlatılar yüzyıllar boyunca kuşaktan kuşağa anonim ve sözlü olarak aktarılmışlardır. Folklor disiplinin başlangıcından itibaren bu türler metin olarak değerlendirilmiş, bağlam dokuları çoğunlukla göz ardı edilmiştir. 1970'lerde folkloristler arasında bu türleri kendi bağlamlarında değerlendirme tartışmaları başlamıştır. $\mathrm{Bu}$ çerçevede halk anlatılarının yeniden söylenmesi hatta onların sergilenmesi de çalışmaların konusu olmaya başlamıştır. Bu makalede, 'Uykudan önce', Somut Olmayan Kültürel Miras Müzesi', 'Dengbêj ve Dengbêj evlerinde Dengbêjlik', 'Mem û Zîn', 'Pîrê û Rovî' gibi Türk ve Kürt halk anlatılarından örnekler verilmiş ve bunlar yakın etkili folklor teorilerinden birisi olan performans teori bağlamında değerlendirilmiştir.

Anahtar Kelimeler: Halk Anlatıları, Türkçe, Kürtçe, Performans teori, Zarok tv.

Recommended citation:

Keskin, N. (2016). Di Çarçoveya Teorıya Performansê De Nırxandına Vegotınên Gelêrî [An Evaluation of Folknarratives in the Frame of Performance Theory]. International Journal of Kurdish Studies 2 (1), pp.51 $-66$.

\footnotetext{
${ }^{1}$ Asst. Prof., Mardin Artuklu University, Institute of Living Languages, Kurdish Culture and Language Department. necatkeskin@gmail.com
} 


\section{DESTPÊK}

Edebiyata gelêrî an jî wek carinan tê binavkirin 'edebiyata devkî' beşeke sereke ya folklorê tê hesibandin (Dorson 1972: Yıldırım \&Pertev\&Aslan 2013). Edebiyata gelêrî ku wek taybetmendiyên xwe yên anonîm û kolektîf di nav civakê de tê afirandin û dîsa di nav şert û mercên civakê de bi nifşên nû re tê veguhastin, di çanda civakekê an jî heremekê de roleke gelekî bingehîn dilîze. Bi vî rengê xwe ji aliyekî ve rewşa civakê dide ber çavan û ji aliyên din ve jî fonksiyonekê di nav civakê de tîne cih. Bêguman li gor guhertinên şert û mercên jiyanê folklor û wek binbeşeke wê edebiyata gelêrî jî rastî guhertinan tê. Di heman demê de ji aliyê bikaranîn û fonksiyona hêmanên edebiyata gelêrî jî guherîn derdikevin meydanê. Ev guherîn dibe ku di ziman de, di 'gotin'ê bixwe de û di 'îcra'kirinê de were xuyakirin.

Îro her diçe ji aliyê teknolojî û her weha ji aliyê ragihandinê ve geședanek berfireh çêdibe û ev yek jî bi xwe re hem ji aliyê xebat û hem jî ji aliyê bikaranîna encamên van xebatan de derfetên nû derdixîne meydanê. Ji aliyê xebatên folklorê ve jî ev pêşketin û geşedan gelekî girîng in. Hem ji bo agahdariya girseyan û di heman demê de jî ji bo xebatên folklorî û bikaranîna vegotinên gelêrî derfetên nû bi xwe re tîne. Di nav van derfetan de bikaranîn, 'pêşkêşkirin' û fonksiyonên 'nû' yên xebatên folklorî di çarçoveya nêrîna performansê de dikarin werin nirxandin. Her weha vegotinên edebiyata gelêrî ya kurdan jî di çarçoveya bikaranîn, 'pêşkêşkirin' û fonksiyonên nû de dikarin werin analîzkirin. Lê pêş̂̂ pewîste çend gotin li ser têkiliya edebiyata gelêrî û folklorê, cihê edebiyata gelêrî di nav teoriyên folklorê de bê gotin.

\section{Folklor û edebiyata gelêrî:}

Folklor beşeke zanistê ye ku bi gelemperî dikare wek lêkolîn, polînkirin, arşivkirin û şirovekirina çanda gelekî, an jî çanda herêmekê bê pênasekirin (Örnek 2000:15). Di bin banê vê beşa zanistî de 4 binbeşên girîng tên diyarkirin ku yek ji wan edebiyata gelêrî (folk literature) an jî edebiyata devkî (oral literature) ye.

Li gor Dorson (1972: 2-5) folklor di bin çar binbeşan de dikare were dabeşkirin. Ev jî;

1-Edebiyata devkî/gelêrî (Oral Literature): Berhemên ku nivîskarê wan ne diyar û bi awayekî devkî belav bûne. Hemû cureyên edebiyata gelêrî di nav vê beşê de tên tomarkirin.

2- Çanda madî: Ev ji teknîk, bikêrî (skill), formûl û tarîfên ku ji nifşan bo yên din hatine veguhastin.

3- Adetên gel ên civakî: Rîtûelên derbasbûnê (initiation rites), adetên têkildarî jidayikbûn, zewac, mirin di nav vê beşê de tên tomar kirin.

4- Bicihanîna (performing) hunerên gelêrî wek muzîka gelêrî, dans û şanoya gelêrî cureyên vê beşề ne. 
Di nav xebatên folklorê de edebiyata gelêrî cihekî girîng digire û saheyeke berfireh e. Carinan wek 'çanda devkî' jî tê binavkirin, lê di navbera çanda devkî û edebiyata gelêrî de cudahiyek heye. Ligel ku edebiyata gelêrî, wek ji nav jî diyar e, hêmanên 'edebî' di nav xwe de dihewîne, 'çanda devkî' tê wateya hemû tiştên ku bi awayekî devkî heta îro hatine (Ong 1995).

Ev tesnîf carina jî wek 'çanda madî' û 'çanda manewî' jî tê binavkirin. Lê îro ji dêvla van binavkirina ve bêhtir 'mîrata şênber ya çandî' û 'mîrata neşênber ya çandî' tê bikaranîn. Ev dabeşkirin û binavkirin di nivîs û belavokên UNESCO de jî tê xuyakirin û beşa ku 'edebiyata gelêrî di nav de wek 'mîrata neşênber' tê pênasekirin. ${ }^{2}$

Edebiyata gelêrî ku parçeyek ji 'mîrata neşênber' e di çanda hemû gelan de cihekî sereke digire. Ew hemanên edebî ku nivîskarê wan ne diyar e û di nav gel de bi awayekî 'anonîm' hatine heta îro di bin banê edebiyata gelêrî de dikarin werin kom kirin û ew jî dîsa dikarin di bin du beşên sereke de werin dabeşkirin:

1-Vegotinên gelêrî

2-Şiîra gelêrî (gotinên stranên gelêrî û dûrik jî dikarin di bin vê beşê de werin dabeş kirin).

Vegotinên gelêrî jî ji mît, destan, efsane, hikayeyên gelêrî, çîrok, gotinên pêşiyan, biwej (îdiyom) û tiştanokan pêk tên (Karadağ 2004).

Berî ku nimûneyên vegotinên gelêrî yên kurdî di çarçoveya bikaranîna wan ya îroyîn de were niqaş kirin, bi kurtasî divê di nav dîroka folklor û teoriyên wê de nêrînek li edebiyata gelêrî were kirin.

\subsection{Di nav teoriyên folklorê de vegotinên gelêrî:}

Xebatên folklorê bi awayekî zanistî bi birayên Grimm re dikare were destpêkirin ku di nav van xebatan de jî xebatên li ser vegotinên gelêrî cihekî sereke digirtin. Birayên Grimm ji çîrok, destan û mîtên gelêrî yên di nav gel de belav bûne dest bi karê xwe yê berhevkirinê kirin. Li gor wan ew 'rihê gel' di nav van vegotinên gelêrî de dikarîbû were dîtin. ${ }^{3}$ 'Rihê gel'

\footnotetext{
2 Ji bo pênaseya 'mîrata çandî' ya UNESCO bnr: http://www.unesco.org/culture/ich/en/what-is-intangibleheritage-00003; û ji bo pênaseya 'mîrata neşênber' jî bnr: http://www.unesco.org/culture/ich/en/convention\#art2 dîroka lênêrînê ya dawî:11.12.2015.

${ }^{3}$ Ev yek rasterast bi fikra netewî ve girêdayî ye. Li gor wê demê ku wek 'dema romantîk' jî tê binavkirin, bingeha 'netewe' an jî 'rihê netewe' di nav gel bixwe de ye û dibe were berhevkirin. Ji bo têkiliya 'folklor û netewîtî'yê bnr: Arzu Öztürkmen (1998), Folklor ve Milliyetçilik. İstanbul: İletişi̇m.
} 
yek ji fikrên fîlozofê Elman Johann Gottfried von Herder bû ku bandor li ser Birayên Grimm û fikra netewetî ya Elmanan kiribû. ${ }^{4}$

Piştî pênasekirina 'folklore' û pejirandina têgehê ji aliyê raya giştî ya akademiyê ve, sazî û weşanên derbareyê xebatên folklorî jî zêde bûn û pê re jî nêrîn û têoriyên vê beşa zanistî jî derketin meydanê.

Folklor jî, bêguman, wek beşeke zanistî girêdayî rewş, nêrîn û niqaşên demê yên ku di akademiyê de tên pejirandin û xebat jî li gor rêbaza van nêrîn an jî teoriyan bi rê ve diçe. Ev yek di pênasekirin, bikaranîn û xebatên folklorê de -hem ên teorîk û hem jî yên saheyî- tê xuyakirin.

Piştî binavkirin û bikaranîna têgeha 'folklor'ê, xebatên di vî warî de jî bêhtir bi rêkûpêk bûn, sazî û kovarên bi navê folklorê hatin sazkirin û weşandin û ev xebatên ku bi 'rihê gel' ve girêdayî û dihat bawerkirin ku bingeha avakirina 'netewe' ye, di nav gelên ku dixwestin nasnameya xwe ya netewî xurttir bikin de berfirehtir bûn.

Ligel ku ji aliyekî ve xebatên folklorê bi vî rengî bimeşin, ji aliyê din ve xebatên li ser teorî û rêbazên folklorê jî dihatin kirin û ev yek jî piranî girêdayî şert û mercên civakî, zanistî, çandî û siyasî bûn. Ji ber vê yekê jî teoriya pêşî ku bandora xwe li ser xebatên folklorî kiriye, nêrîna giştî ya wê demê peresenparêzî (evolutionarism) ye.

Wekî tê dîtin, xebatên folklorê ku bêhtir li ser vegotinên gelêrî ${ }^{5}$ dirawestiyan bi xebatên qadî destpêkirin û di nav wan de jî berhevkirin rêjeyeke gelekî giran digirt û ev berhem an jî xebat jî bêhtir bi şêweyeke dîakronîk (diachronic) ${ }^{6}$ dihatin nirxandin. ${ }^{7}$ Ev yek bi du nêrînên sereke ve girêdayî bû; yek jê peresenparêzî û ya din jî neteweperwerî. Wek mînak çavkaniyên eslî yên vegotinên gelêrî, koka wan, bê ji ku û çawa derketine mijarên eslî yên vê demê bûn û her weha jî nêrîn û toeriyên wê demê jî li ser vê bingehê hatibûn damezrandin.

Nêrîn an jî rêbaza 'dîrokî-erdnîgarî ya Fînî' û 'teoriya dîrokî' dudu ji van teoriyan in ku bêhtir li ser 'kok' û 'dîroka' vegotinên gelêrî disekinin. ${ }^{8}$

Bêguman wek li jor jî hat gotin ev ramanên di folklorê de ji nêrînên giştî yên zanistên civakî û şert û mercên siyasî, çandî û civakî ne dûr bûn û bi wan re têkildar bûn. Her weha xebatên li ser 'kok' û 'dîrok'a keresteyên folklorê dirawestiyan jî bêhtir di bin bandora peresenparêziyê (evolutoniarism) de -teoriya serdema 19mîn ya giştî di zanistên civakî de-

\footnotetext{
${ }^{4}$ Ji bo teoriya Herder ya 'rihê gel' (volksgeist) bnr: http://www.counter-currents.com/2011/05/herders-theory-ofthe-volksgeist/print/ -dîroka lênêrînê: 09.10.2015.

${ }^{5}$ Vê yekê bandor li ser pênaseya têgeha 'folklor'ê bi xwe jî kir ku wextekî gelekî dirêj folklor û edebiyata gelêrî di heman wateyê de hatin bikaranîn. Ji bo pênaseya folklorê ya pêşî bnr: Richard M. Dorson-William J. Thoms (1997).

${ }^{6}$ Ji bo 'diachronic' di kurdî de peyv tune ye, di nav ferhengên ingilizî-kurdî jî ev peyv me nedît. Her çiqasî wek 'xebatên paşdeçuyî' an jî 'dîrokî' werin bikaranîn jî, ji bo niha me wek 'diakronik' nivîsand.

${ }^{7}$ Özkul Çobanoğlu, Sözlü Kompozisyon Teorisi ve Günümüz Halkbilim Çalışmalarındaki Yeri, Folkloristik, 1998, ankara.

${ }^{8}$ Aslan (2012: 85) van teoriyan wek 'teoriyên metîn-navendî' binav dike ku yek ji wan' ekola fînî ya dîrokîerdnîgarî' ye din jî 'ekola binyadgerî' ye.
} 
bûn. ${ }^{9}$ Ji aliyê din ve wek diyardeyek civakî fikra neteweperwerî jî her diçû geş dibû û vê yekê jî bandor li ser xebatên folklorê dikir.

Bêguman, guherînên di civakê de bandora xwe li zanistê jî dikir û di nav demê de bi guherînên civakî re nêrîn û teoriyên zanistên civakî jî xwe adapteyî van guherînan kirin. ${ }^{10}$ Her weha nêrînên di beşeke zanistê de jî bandora xwe li beşên din dikir/dike. Folklor jî wek beşek ji zanistên civakî ji van guherînan bêpar nema û nêrîn û teoriyên cuda di vê qadê de jî derketin meydanê.

\subsection{Teoriya performansê û vegotinên gelêrî:}

Pêşfikrên teoriya performansê dikarin di nêrînên antropologên serê sedsala 20mîn ên wek Edward Sapir û Bronislaw Malinowski de werin dîtin. Lê bêhtir bandora 'zimannasiyê' ku di salên 1920an bi pêş dikeve û bi navê 'Dibistana Zimannasiyê ya Pragê' tê zanîn xuya dike. 1960-70an de jî di xebatên folklorê de derdikeve pêş ku ev yek bi xwe bi rewşa civakî ya wê demê, eleqeya ciwanên wê demê ku wek 'nifşa hippî' tên zanîn ve têkildar xuya dike (Çobanoğlu 2012: 292-293).

Piştî salên 1960î di folklor û etnografyayê de nêrîn ji berhevkirin û kategorîzekirinê ber bi sentez û famkirina gelan û afîrandinên li gorî fama wan ve hate guhertin (Magoulick, 2015). Ev nêrîn û guhertin, ligel her tiştên din, ji bo teoriya performansê di folklorê de bû bingehek. Ji wê demê û bi vir de nêrînên folklorzanan ji 'text'ê (metin) ber bi 'context'ê (kontekst) ve guherîn. Êdî bêhtir li ser 'îcrakirin'a vegotinên gelêrî dihat rawestin. Ev yek bêhtir wek nêrînên 'kontekstî an jî performansê hatin naskirin. Heta wê demê berhevkirin jî di nav de xebatên folklorî bêhtir li ser 'metinê' (text) disekinîn. Wek Aslan (2012:85) jî tîne ziman;

"Heta îro, ne xelet e go were gotin ku bingeha xebatên li ser çîrokên ji derdora çanda devkî hatine berhevkirin û derbasî nivîsê bûne bêhtir teoriyên metînnavendî, wek 'Ekola Fînî ya Dîrokî-Erdnîgarî' û 'Rêbaza (Morfolojîk) Binyadgerî', kirine".

Lê belê piştî vê nêrînê êdî bal ji metnê bêhtir diçe ser 'îcra' û 'pêşkêşî́ya hêmanên folklorî. Nunerên vê nêrînê wek nimûne ji berhevkirina çîrokêkê bêhtir giringî didin ser çîrokbêj, jest û mîmîkên wî/ê, derdora vegotinê, peyam û bandora wê vegotinê li ser derdorê.

\footnotetext{
9 Ji bo teoriyên zanista civakî bnr: S. Özbudun \& B. Şafak \& N. S. Altuntek (2007) Antropoloji: Kuramlar/Kuramcilar. Ev xebat her çiqasî ji bo 'antropolojî'yê be jî, ji ber ku antropolojî, etnolojî û folklor beşên bi hev re gelek têkildarin dikare fikrekî ji bo xebatên folklorê jî bide xuya kirin. Ji xwe derketina teoriya performansê di xebatên folklorê de jî îlhamê ji bi xebat û nêrînên antropologan distîne. Bnr: Özkul Çobanoğlu (2012:288-289).

${ }^{10}$ Ji bo teoriyên folklorê bnr: Richard M. Dorson (1972), 'Concept of Folklor and Folklife Studies' Folkor and Folklife, an Introduction (ed. Richard M. Dorson), The Universtiy of Chicago Press: Chicago, r. 1 50). Bi Özbudun û ed.( 2007) re berawird bikin.
} 
Bi gotineke din, nûner û alîgirên vê teoriyê êdî ji metnê bêhtir bal didin ser bikaranîn, afirandin û pêşkêşkirina hemanên folklorê û bi vê yekê di civakê de fonksiyona folklorê derdixin pêş (Ersoy 2004).

Bi vê nêrînê re êdî hêmanên vegotina gelêrî an jî yên 'çanda devkî' ji hêmanên ku kevn bûne û bûne fosîl derdikevin û dibin hemanên ku di nav jîyanê de ji nû ve derdikevin tên nirxandin. Bi vê yekê jî disîplîna folklorê jî ji wê disîplîna ku bi tiştê 'kevnar' re eleqedar dibe derdikeve. Li gor Ruhî Ersoy;

"Ev têgeha ku em behsa wê dikin [yanî performans], ji bo famkirina metnê ji fikra famkirina derdora ku metn lê tê gotin derketiye, bi adaptasyona xebatên antropolojî li ser berhemên çanda devkî dest pê kiriye û pêşketinan jî şiklê xwe yê îro sitandiye" (Ersoy 2004).

Wek li jor jî hat bilêvkirin, xebatên ku bi vê nêrînê tên kirin ji metinê bêhtir girîngiyê dide îcrakirin, şert û mercên îcrayê û derdorê û xebatên xwe bi vî awayî dike. Her weha ev nêrîn unsurên wek cihê ku ew berhem tê gotin (îcrakirin), wext, mekan, şêwe, nasnameya vebêjer wek kontekst dinîrxîne û van unsuran dixe nav xebata xwe de. Êdî hêmanên folklorî, wek nimûne vegotinên gelêrî, ji çarçoveya 'tiştên kevin' an jî ji kategorîzekirina bermayiyên demên kevin derdikevin û ji ber ku ev berhem di hafizeya gel de hatine parastin, bi nifşên nû ve hatine veguhastin û ji ber ku ev yek didome jî wek berhemên zindî di nav civakê de tên nirxandin.

Bi vê nêzîkbuyînê ev nêrîn xwe ji niqaşên li ser 'kok'ê dûr dixe û li ser bikaranîna wan hûr dibe. Di vê çarçovê de vegotinên gelêrî di her demê de bi riya ku xwe li gor şert û mercên civakê, li gor derdorê (kontekst) û vebêjan biguhere gihajtiye roja me ya îro. Ev yek jî wan ji wê çarçova 'cemidî' û sar derdixe û bi awayekî din wek tiştekî ku diherike derdixê ber çavan. Ev nêrînên ku heta niha di vir de hatine bilêvkirin di gotin û xebatên nûner û alîgirên 'teoriya performansê' de jî tên dîtin.

Alan Dundes, ku yek ji sereke folklorzanên teoriya performansê ye, li ser pênase û tehlîlkirina berhemên folklorê girîngiya tevn (texture), metin (text) û kontekstê (context) tîne ziman û dibeje ku bi van her sê ûnsuran berhemeke folklorê dikare were pênasekirin û tehlîlkirin. Di virde tevn (texture) bêhtir bi taybetmendiyên ziman ve girêdayî ye. Metin berhem bi xwe ye. Yanî her vegotinek gelêrî, an jî berhemek folklorî bi xwe metin e. Ligel ku tevn nikare bê wergerandin bo zimanên din, metin dikare bê wergerandin. Konteks jî şert û mercên derdorê ku berhem tê de tê gotin an jî afirandin, hilberandin (Dundes 1998).

Dîsa gava Dundes xebatên folklorê yên dema xwe rexne dike dibeje ku folklornas bêhtir li ser metinê disekinin, tevn bi zimanzanan ve berdane û kontekst jî hatiye paşguhxistin. 
Ji aliyên din ve her çiqasî di heman cihî de Dundes bibeje ku kontekst û fonksiyon dibe ji hevdu werin cudakirin jî, dikare were gotin ku fonksiyona berhemeke folklorî girêdayî konteksê ye û li gor konteksê jî diguhere. ${ }^{11}$

Xebatên folklorê ku îro tên kirin, an jî xebatên folklorî ku li ser malperan, li ser dikê şanoyan, an jî di televizyon û muzeyan de tên 'pêşkêşkirin' jî di vê çarçovê de dikarin werin nirxandin. Çîrok, pêkenok, çîrokên gelêrî û heta gotinên pêşiyan careke din, 'ji nû ve' tên bikaranîn, di civakê de fonksiyonekê bi kar tînin. ${ }^{12}$

Edebiyata gelêrî ya kurdan û bikaranîna berhemên wê di dema îro de hem ji aliyê fonksiyon û hem jî ji aliyê bikaranînê de dikarin di vê çarçoveyê de werin analîzkirin.

\section{Ji nû ve 'bikaranîn'a vegotinên gelêrî:}

Ji bo ku 'jinuvebikaranîn' were famkirin divê pêşî bersiva vê pirsa sereke were dayîn: Xebatên folklorî ji bo çi tên kirin? Ji bo çi keresteyên folklorî tên berhevkirin, tesnîfkirin, arşivkirin û şirovekirin?

Wek her beşeke zanistê û zanistên civakî jî, armanca xebatên folklorê jî di serî de 'famkirina' derûnî, binyada civakî ya gelekî an jî heremekê ye, û di vê çarçovê de dîsa famkirin û têgihiştina têkiliya wî bi paşerojê ve, bi erdnîgarî, siruşt û derdora wê ve ye. Ji bilî vê armanca sereke, hinek tiştên din hene ku xebatên folklorê girîngiyê didin ser û wek armancê ji xwe re nîşan dikin. Ew jî bi vî awayî dikarin werin amajekirin;

-Naskirina çanda 'xwe' (berhevkirin û tesnîfkirin)

-Parastina çanda 'xwe' (arşîvkirin)

-Danasîna çanda 'xwe' (şirovekirin).

Êdî ev çanda ku hatiye 'naskirin' û 'parastin' divê bi nifşên nû ve were veguhastin ku ew jî di çarçoveya 'jinuveşirovekirin' de dikare were xwendin û dîsa di vir de perwerdehiya zarokan an jî bi giştî perwerdehî jî di nav vê yekê de cîh digire. Ev xala dawî wek li jor jî bi kurtî hat behskirin pêşî bi hişmendiya neteweyê ve girêdayî ye. Êdî 'çand'a ku hatiye 'naskirin' û 'parastin' di konteksteke 'nû' de, ji bo ku nifşên nû 'çanda xwe ji bîr nekin û hîn bibin', bi

\footnotetext{
${ }^{11}$ Dîsa Dan-Ben Amos jî folklornasekî parezvanê vê teoriyê tê naskirin. Xebata wî bi navê 'toward a folklore definition in to context' (1971) girîng e. bnr. Ben-Amos (1971).

${ }^{12}$ Di serdema me de tişta herî sereke ku di nav jiyana me de cih digire internet û teknolojî ye û ev yek wek her tiştî bandorê li vegotinên 'gelêrî' jî dike. Ji bo xebatek nû li ser vê mijarê di derbarê 'gotinên pêşiyan' ên tirkî û 'guherîn' wan bnr. Uğur Başaran (2013), "Atasözlerinin Kalıpsallı̆̆ Üzerine", Turkish Studies, Volume 8/9 Summer 2013, s. 760. Ji vê xebatê mînakek dê mebestê rave bike. Gotineke pêş̧yan ya tirkî 'aynı ipte iki ayı oynamaz' (li ser heman werîsî du hirç nalîzin) îro li ser malperên înternetê bi awayê 'Aynı ip'de iki bilgisayar oynamaz' (Di heman ip'de di compûter naxebitin)' belav dibe û tê bikarinîn.
} 
şêweyeke nû tê pêşkêşkirin, 'îcrakirin' an jî şirovekirin. ${ }^{13}$ Perwerdeya zarokan jî ku dikare wek armanceke din ya xebatên folklorî were gotin, bi xwe bi performansê (îcrakirin) ve têkildar e.

Di vir de berî ku em derbasî mînakên kurdî bibin hinek mînak ji derdorê dê mebest û hizra gotarê zelaltir bike. Bêguman di vê mijarê de gelek mînak hene ku werin dayîn. Ji lîstikên gelêrî ku bi awayekî 'nû' û 'standartîzekirî' heta şanoya gelêrî, bikaranîna çîrokan di sînema û televîzyonê de yelpazeyek gelekî berfireh heye. Ji aliyên din ve di şanoyên ji bo zarokan de jî mînakên zêde hene û gelek caran jî çîrok bi awayekî 'nûjen' tên pêşkêşkirin. ${ }^{14}$ Lê li vir sê mînak jî ji bo mebesta vê gotarê dê bes bin.

Mînaka pêşî bernameya 'Uykudan Önce' (Berî Xewê) ya TRTyê ku di salê 1980yî de dest pê kiri bû ye. Ev bername ji aliyê şanoger û lîstikvana sînemayê Adile Naşit ve di TRTyê de dihat pêşkêşkirin. Di bernameyê de Adile Naşit ${ }^{15}$ wekî 'xaltiya çîrokbêj' (Masalcı Teyze) dihat binavkirin û berî xewê wek pîrikên çîrokbêj ên berê ji zarokan re çîrok û mesele digotin. Lê di demê berê de têkiliyek rû bi rû hebû bi guhdaran re, lê di bernameyê de ev yek hatiye guhertin û êdî têkiliya 'vebêjer' û 'guhdarvan' bi şêweyeke ne rasterast pêk tê. Her çiqasî di vir de têkiliya metn (text) û kontekstê (contekst) hatibe guhertin jî fonksiyona ku di civakê de bi kar tîne nehatiye guhertin û di ser de jî bi riya televîzyonê ev 'sînor'ê vê bikaranînê firehtir buye. Êdî 'xaltîka çîrokbêj' ne ew pîrika ku li malê ji sê-çar zarokan re çîrokan dibeje an jî şîretan li wan dike, lê ew bi riya bernamê dibe 'xaltîka çîrokbêj' ya hemû zarokan. Ji aliyê din ve bi vê yekê çand ji nû ve tê zindîkirin û zarok dîsa bi riya vê bernamê û 'xaltîka çîrokbêj' çanda ku di nav de dijîn nas dikin.

Mînakeke din ya balkêş dîsa ji Tirkiyê 'Mûzeya Mîrata Çanda Neşênber' (Somut Olmayan Kültürel Miras Müzesi) ya li Enqerê ye. ${ }^{16}$

Ev muze di sala 2013an de bi hevkariya beşa 'Gelnasiya Tirkan' (Türk Halkbilimi) û şaredariya Altındağ ya Enqerê ve hatiye vekirin. Wek ji navê wê jî tê famkirin ev muze ji muzeyên ku berhemên dîtbar di hundirê wan de tên pêşkêşkirin cuda ye û bêhtir berhemên ji 'çanda devkî' an jî 'çanda neşênber' tên 'pêşkêş̧kirin'. Karagöz-Hacivat, cureyên şanoya gelêrî (orta oyunu, meddah) û lîstikên zarokan, hinek ji lîstikên gelêrî ne ku di vê muzeyê de pêşkêşî mevanan tên kirin. Dîsa hunerên gelêrî wek 'Ebrû' jî di vê muzeyê de bi mêvanan re tê tetbîqkirin. Ji aliyê din ve cureyên edebiyata gelêrî wek çîrokên Enqerê û yên deverên din,

\footnotetext{
${ }^{13}$ Her çiqasî ev bi hişmendiya netewî ve girêdayî be jî, divê aliyê wê yî 'mirovahî' neyê paşgûhxistin û neyê jibîrkirin. Ji ber ku her mirov, bi giştî jî zarok, bêhtir bi zimanê xwe yên dê û bavan, bi çanda ku di nav de mezin dibe, bi motîfên çanda xwe dikare hîn bibe û dinyayê nasbike.

14 Ji bo şanoya zarokan mînakeke guncav 'Mîhrîcana Navnetewî ya Şanoya Zarok û Ciwanan ya Mêrdîn'ê (Uluslararası Mardin Çocuk ve Gençlik Tiyatro Festivali) dikare were nîşan kirin. Di navbera 03-08ên Cotmeha 2015an de ya 6mîn hat lidarxistin. Hem di bernameya 2015 an hem jî di bernameyên berê de lîstîkên ji çîrokan hatine wergirtin cih digirin. Ji bo agahiyê berfireh bnr: http://mardintiyatro.org/festival-2015/; û http://mardintiyatro.org/wp-content/uploads/2015/11/MardinKatalog-2015-dijital.pdf -dîroka lênêrînê: 20.12.2015

${ }^{15}$ http://www.sinemavesinema.com/adile-nasit-vefatinin-28-yilinda-sevenleri-tarafindan-anildi-c3237.html; Ji bo jiyana Adîle Naşit bnr: https://tr.wikipedia.org/wiki/Adile_Naşit dîroka lênêrînê: 20.12.2015

${ }^{16} \mathrm{Ji}$ bo agahiyên berfireh derbarê mûzeyê de bnr: http://www.kulturelmirasmuzesi.com/index.php; http://turk_halkbilimi.gazi.edu.tr ; ; $\quad$ http://www.ankarakultur.gov.tr/servisler/kultur-ve-tabiatvarliklari/muzeler/somut-olmayan-kulturel-miras-muzesi -dîroka lênêrînê:15.11.2015
} 
gotinên pêşiyan, stran, lorî di vê muzeyê de careke din ji mêvanan re û bi wan re tên gotin, an jî 'pêşkêşkirin'. Êdî ev hêmanên çanda neşênber ku ji sedsalan gihaştine roja îro bi awayekî din û bi wateyeke din tên dubarekirin û bi vî awayî jî nifşên nû van berhemên gelêrî nas dikin û her weha zarokên ku vê derê zîyaret dikin hînî çanda xwe dibin an jî bi riya çîrokan 'perwerde'yekê distînin.

Bi gotineke din, ji aliyekî ve muze karê xwe yê sereke yanî parastin û danasîna çandê dike û ji aliyekî ve bi riyeke din, bi şêweyeke din van berhêmên 'çanda neşênber' ji nû ve dihilberîne. Yanî metn (çîrok, lîstik hwd.) di nav kontekseke nû (di muzeyê de) bi tevneke cuda (ji hêla kesên ku li wir dixebitin) ji nû ve tên hilberandin. Wek mînak, mêvanên ku tên odeya ku Karagöz-Hacivat tê pêşkêşkirin dikevin nav kontekseke din de. Li vir êdî ne tenê temaşekirin lê ji aliyê din ve tevlîbûn jî pêk tê. Çi zarok, çi mezin kesên ku dikevin vê odê de bi awayekî tevlî lîstikê dibin. Ya li zengil dixin, ya vekirina lîstikê dikin û dilîzin ku ev bi xwe performanseke nû ye ku li ser emprowîzasyonekê tê avakirin.

Zarok an jî mêvanên din ku dikevin odeya çîrokan de jî bi heman rengî dikevin nav kontekseke din de. Li vir êdî ew çîrokbêjên di nav gel de dijîn diçin, çîrokbêjên 'xwende' û çîrokên 'standart' derdikevin meydanê. Di beşên din ên muzeyê de jî heman tişt dikarin werin dîtin.

Mînakên ku heta neha hatin dayîn, li gor teoriya performansê ji aliyekî ve ji nû ve zindîkirina folklorê ye. Aslan referans dide folklornas İlhan Başgöz û weha dibeje;

"Tu şêwe an jî metnek sabît yên berhemên ku di hawirê çanda devkî de hatine hilberandin tune ye. Metinên cuda yên van cureyan ku di demên cuda yên îcrakirinê û mêkanên cuda de hatine afirandin hene. Li ser metna ku di her îcrayeke de 'ji nû ve hatiye afirandin', hostatiya vebêjer ya di îcrakirinê de, asta perwerdehiyê, temên, statuya civakî, baweriyên olî, daraziyên ehlaqî, bi kurtî nasname û şexsiyeta wî/wê bandorê dike, ev ûnsur şekil didin metnê" (veg. Aslan 2012: 86).

Ev jî careke din dide xuyakirin ku folklor ne tenê tiştekî ku di paşerojê de cemidî maye, lê li gor dem, derfet û rewşa giştî tiştekî ku ji nû ve tê 'afirandin' an jî bikaranîn. Ji ber ku kesên ku dibêje, kesên ku guhdar dike û metin yanî (vegotin) bi xwe tê guhertin.

Çîrokên ku di televîzyonan de tên gotin jî di heman çarçovê de dikarin werin nirxandin. Wek di mînaka jor de hat dîtin (Uykudan Önce) vebêjer, têkiliya vebêjer û guhdarvanan, rewşa ku tê de çîrok tên gotin tev hatine guhertin û êdî bi şêweyeke din û bi wateyeke din vegotin careke din 'tên afirandin'. ${ }^{17}$ Heman tişt ji bo çîrokên ku wek 'xêzefîlm' tên 'pêşkêşkirin' an jî gotin jî dikare were gotin. Êdî di van bernameyan de 'çîrokbêj'

\footnotetext{
${ }^{17}$ Li vir careke din divê were gotin ku bi riya televîzyonê hêmanên edebiyata gelêrî ji hêla bêhtir kesan ve tên 'guhdarkirin'. Bi vê yekê jî bêhtir kes, piranî jî nifşên nû çanda 'xwe' nas dikin ku ev yek van berhemên edebiyata gelêrî bi 'wate' dike.
} 
televîzyon bixwe ye, û çîrok ne ku tê guhdarkirin lê tê temaşekirin. Berî ku ji bo çîrokên kurdî mînak bên dayîn, mînakek ji derve dê mijarê hinekî zelaltir bike.

CN (Carton Network) qenaleke televîzyonê ye ku li ser satelaytê weşanê dike. Zimanê wê jî bêhtir bi ingilîzî ye. Bernameyên televîzyonan jî bêhtir ên ji bo zarokan li welatên din ji çanda wan tê û gelek caran jî ji edebiyata gelêrî, ji çîrok û hikayeyên gelêrî pêk tên.

Di vê qenalê de her çiqasî bêhtir 'çanda ingilîzî' û lehengên (kevin û nû) yên wê çandê tên pêşkêşkirin, carinan jî ji çandên cihanê jî mînak tên dayîn. Yek ji wan ku îro di bernameya CN (Cartoon Network)ê de cih digire jî çîrokên 1001 şevê ne. Ev çîrok wek anîmasyon an jî 'xêze-fîlm' di bernameyê de tên pêşkêşkirin. Lê wek ku di vir de jî tê dîtin, û wek ku di 'nêrîna performansê' de jî tê diyar kirin, çîrok bi awayekî din tê gotin û ev yek jî careke din dide xuyakirin ku her gotinek 'jinûvegotin'e. Di vê xêzefîlma bi navê 1001 şevê de çîrokbêj wek di weşanê de jî 'şehrazad' e, yên ku ji wan re tên gotin jî 'şehrzaman û dunyazad' in. Her du jî, bêhtir jî 'Şehrzaman' di vê bernamê de wek zarokekî 'netebte' tê xuyakirin, û 'Şehrazad' ji bo ku şiretan bide wan çîrokan ji wan re dibeje.

Di wir de, çîrokên 1001 şevê ku mîrateke ji rojhilata navîn e, bi hinek guhertinên biçûk tên bikaranîn û ev yek jî bala zarokan dikişîne û wan bi çanda Rojhilata Navîn dide naskirin. ${ }^{18}$ Ev yek jî ji bo 'jinûvebikaranîn'a vegotinên gelêrî û teoriya performansê mînakeke balkêş e.

\section{Vegotinên gelêrî yên kurdî û performans:}

Piştî van mînakan gelo vegotinên gelêrî yên ji folklora kurdî çawa 'ji nû ve tên bikaranîn'? Gelo di nava konteksa nû de bi çi şêwe û wateyê tên pêşkêş̧irin? Kijan mînak di vê çarçoveyê de dikarin werin nîşankirin? Ev tev de ji aliyekî ve bi rewşa çalakiyên kurdan ve girêdayî ne.

Xebatên folklora kurdî, dikare were gotin ku, her çiqasî di asta berhevkirinê de bin jî xebatên analîz, şirove û berawirdiyê jî hêdî hêdî derdikevin pêş. ${ }^{19}$ Her weha 'bikaranîn'a wan, an jî 'jinûvevegotin'a wan jî êdî xuya dike.

Wek di serî de jî hate gotin, geşedan û pêşketina di warê teknolojî û ragihandinê de bandor li ser xebatên medyaya kurdî jî kirine. Dikare were gotin ku di pêşkêşkirina hemanên folklora kurdî de sazî û amurên ragihandinê roleke girîng dilîzin. Di vî warî de kurd jî gelek dixebitin, televizyon û radyoyan vedikin. Her çiqasî ev radyo û televizyon bêhtir di warê

\footnotetext{
${ }^{18}$ Di vê bikaranînê de 'sterotîpkirin' jî dikare were niqaşkirin, lê ji ber ku ev li derveyî mijarê yê dê li ser neyê rawestandin.

${ }^{19}$ Wek mînak di pirtûka 'Edebiyata Kurdî ya Gelêrî' ku edîtoriya wê Ramazan Pertev kiriye gotarên cur bi cur li ser edebiyata gelêrî hene. Gotara Hayreddin Kızıl \& Veysel Tanrıkulu (2015) ya bi navê "Berawirdkirina çîroka Hedlîlik Bedlîlik a bi Kurdî bi Gur û Heft Karikan a Birayên Grimm re" jî di warê berawirdkirinê de wek xebatek nû dikare were nîşankirin.
} 
siyasî de çalak xuya dikin jî, di demên dawî de hinek hewldanên di warê çandê de jî derdikevin meydanê. Êdî çîrokên gelêrî di televîzyonan de tên bikaranîn ku ev yek ji aliyekî tê wateya 'jinûvebikaranîn'a van çîrokan.

Ji aliyê din ve di bin banê şaredariyan de navendên çandê hatine vekirin û li van deran xebatên li ser çandê, li ser edebiyata gelêrî tên kirin, hêmanên folklorê ji edebiyata gelêrî pêşkêş̂i gel tên kirin. Li vir sê mînak dê werin dayîn ku ji hêla metin, tevn, û kontekstê dikarin werin şirove kirin. Yek ji wan dengbêjî û malên dengbêjan e.

Dengbêjî̀, di nav civaka kurdan de wek formeke veguhastinê cihekî sereke digire û îro ji hêla kurdan ve bêhtir wek formeke 'netewî' tê nirxandin. Dengbêj kî ye? Çi dike? Dengbêj ew kes e ku bi dengê xwe rih û can dide serpehatiyên berê, û wan serpêhatiyan careke din bi dengê xwe -û carinan jî bi alîkariya bilûra xwe- di hafizeya çandî ya gel de zindî dike. Ji vê yekê jî tê xuyakirin ku ev wek bardên Keltan an jî griotên Efrîkayê barkêşên hafizeya çandî yê di nav kurdan de ne. Bêguman di nav folklora kurdan de ne tenê dengbêjî lê hinek formên din ên veguhastinê, an jî vegotinê hene, lê wek li jor jî hat gotin van salên dawî wek formeke 'netewî' tên nirxandin. Vekirina 'malên dengbêjan' li Diyarbekirê ji hêla Şaredariya Mezin ya Bajêr jî vê yekê dide xuyakirin. ${ }^{20}$

Dengbêj wek ji peyvê jî tê xuyakirin ji du peyvan pêk tê û tê wateya 'hostayê deng' (Hamelink \& Barış 2014). ${ }^{21}$ Dengbêj û dengbêjî heta salên 1980yî di nav civaka kurdan de wek kevneşopiyekê cihekî girîng digirt. Ji aliyekî ve pêşketinên teknolojîk, belavbûna radyo û televîzyonan, koça ber bi bajaran, yanî ji ber sedemên civakî, çandî û siyasî ev kevneşopî ber bi windabûnê ve çû. Piştî salên 2000î Şaredariya Bajarê Mezin a Diyarbekirê cihek bi navê 'mala dengbêjan' vekir û dengbêjên ku bêhtir li malan, li ber derê 'camiya mezin' ya Diyarbekirê, an jî li qehweyan şer û serpêhatiyên berê digotin, wek karmend li wir bi cih kirin. Di vê mînakê de dikare were dîtin ku hem di kontekst û hem jî di tevnê de guherîn çêbûye. Êdî ew metnê berê (şer, serpêhatî hwd.) di kontekst û tevneke nû de 'ji nû ve' tên bikaranîn. Di vê çarçoveyê de têkiliya guhdarvan û vebêjer jî guheriye. Ji aliyê din ve guhdarvanên ku hevdu nasdikin an jî têkiliyeke wan bi hevdu re an jî bi dengbêj bi xwe re heye jî ne 'yên berê' ne. Ji hemu çîn û koman cur bi cur mirov tên li wan guhdar dikin. Ji vî alî ve ev 'çalakî'ya 'nû' bi şêweyeke din, di konteksteke 'nû' de tê 'pêşkêşkirin' ku hemu xalên 'nêrîna performansê' ne.

Di heman çarçovê de dîsa lîstika şanoyê ya 'Şanoya Bajarê Mezin a Diyarbekir' a bi navê 'Mem û Zîn' ku ji eposa 'Memê Alan' hatiye adabtekirin jî wek mînakeke din dikare werê dayîn. Ev şano di sala 2014an de li Qesra Mala Cemîlpaşa ku wek 'muzeya bajêr' tê bikaranîn hat 'pêşkêşkirin'. Di vê pêşkêşkirinê de dîsa tê dîtin ku metin, tevn û kontekst bi awayekî 'nû' hatiye bikaranîn. Êdî li Diyarbekir, di 'muzeya bajêr' de 'Memê Alan' tiştekî din ji guhdarvanên xwe yên 'nû ' re dibêje.

\footnotetext{
${ }^{20} \mathrm{Ji}$ bo formeke din û berawirdiya wê bi dengbêjiyê re bnr. Necat Keskin (2015a). Tûr-Abdin'de Bir Kimlik ve Anlatım Biçimi: Mıtırblar ve Mitrıplık. Folklor/Edebiyat, c. 21, sayı.84, (2015/4), r. 57-72.; (2015b). Mitirb û Mitirbî: Nasname û Vegotin. Wêje û Rexne, hj. 6, r. 109-120.

${ }^{21}$ Ji bo pênaseya Dengbêjî û cihê wê di muzîka kurdî de bnr. Mehmet Uzun (2001) û Erol Mutlu (1996).
} 
Ji hêla 'jinûvevegotin' an jî 'bikaranîna vegotinên gelêrî de mînakeke din jî ya îroyîn televizyona bi navê 'Zarok.tv' ye. Zarok Tv di sala 2015an de dest bi weşana fermî kiriye. Wek ji navê wê jî tê xuyakirin ji bo zarokan e û tê de bernameyên zarokan hene. Lê her çiqasî bi kurdî jî be anîmasyon û xêze-fîlmên wê ji çanda kurdan dûr û bêhtir ji derve ne. Wek mînak tê de 'Şînok', 'Rêzikên Angelo', 'Mêşhingiv Maya', 'Mala Foster', 'Gumball', 'Sifînc Bob', 'Pocahontas' ku hemû ji çand û 'çîrok'ên derve ne tê de cih digirin. Sedemên vê yekê piranî madî û teknolojîk û nebûna van bernameyên bi kurdî ye. ${ }^{22}$ Lê dîsa jî ji aliyê 'danasîna' çandê ve tiştên 'xwemalî' wek 'Zarokîstan', 'Fêrgeh', 'Hunerên Destan' jî xuya dikin. Her weha ji bo çîrokên gelêrî jî bi navê 'hebu tune bû' bernameyek he ye ku bi ya 'İyi Uykular' (xew xweş) ya tirkî ku wek mînak li jor hatibû dayîn he ye. Dîsa wek heman mînakê 'Hebû Tune bû' jî her roj di saeta 21.00an berî xewan derdikeve pêşberê zarokan. Di vê bernameyê de lîstikvan xwe xistiye dirûvê pîrekî û ji zarokên derdora xwe re çîrokan dibêje. Tiştên ku li jor di çarçova teoriya performansê de ji bo 'iyi uykular' hatibû gotin, ji bo vê mînaka kurdî jî derbasdar e. Di vir de jî, dîsa tê dîtin ku metin (çîroka standartîzekirî), kontekst (mekanê ku çîrok lê tê gotin an jî performans tê kirin) û tevn ku bi her du xalan ve girêdayî ye hatiye guhertin. $^{23}$

Di çarçoveya mijarê de mînakeke din dikare were nirxandin ku girêdayî 'şanoya zarokan' û bikaranîna çîrokên gelêrî di şanoyê de ye. Hem ji ber ku di nav de 'tevger'ek heye û hem jî ji ber ku 'ji nû ve tê gotin' ev mînak ji bo mijara vê gotarê muhim e. Di vî warî de ji bo bikaranîna çîrokên gelêrî yên kurdî zêde mînak tune ne. Yek ji wan jî 'şanoya bi navê 'Zimzim' e ku li Mêrdînê xebatên xwe didomînê. Li gor yek ji damezrînerên wê, Bilal Korkut, şano di 2014an de ligel çend hevalan ji bo zarokan tê avakirin. Di sala 2015an de jî çîroka bi navê 'Pîrê û Rovî' lîstine. ${ }^{24}$

Di 'pêşkêşkirin'a çîrokan de, hemû armancên folklorê ku li jor hatibûn rêzkirin (danasîn, parastin, perwerde) dikare were dîtin. Ji bo zarok û çîrokan ev yek bêhtir derdikeve pêş. Wek Korkut dibêje;

"Çîrok û zarok du hêmayên bi hev re giredayî ne. Me jî hewl da ku em wan her du hêmayan di yek beroşê de cardin bikelênin" (Bilal Korkut, 2016)

Di vê çîroka ku li ser dikê bi awayekî tevgerî tê 'gotin' êdî forma xwe jî diguhere û dibe 'vegotineke nû'. Yanî, "her karekter ji çîrokê derdikeve ser dike û çîrokê zindî dike. Çirok zêdetir gotin e, lê ku derdikeve ser dike ji gotine behtir dibe tevger" (Bilal Korkut, 2016).

\footnotetext{
${ }^{22}$ Di vir de tiştê ku dikare were rexnekirin ew e ku ji bo kurdî û zarokên kurdan ev bername gelekî kêm in û divê bêhtir werin çêkirin. Bêguman sedemên vê yekê gelek in ku dibe mijara gotareke din û ji ber vê yekê jî tenê bi vê rexnê em dê bihêlin.

${ }^{23} \mathrm{Ji}$ bo bernameyên Zarok tv û nemaze ji bo 'hebû tune bû' bnr: http://zaroktv.com.tr/Kurmanci/Program/Hebtune-b dîroka lênêrînê ya dawî:19.01.2015

${ }^{24}$ Agahiyên derbarê Şanoya Zimzim û xebatên wê ji damezirînerê wê Bilal Korkut hatine sitandin. Hem bi riya hevdîtin û hem jî bi riya e-maîlê ev agahî hatine bidestxistin. Hevdîtin li Mêrdînê di 19.01.2015an de hatiye kirin. Bilal Korkut, di van hevdîtinan de, li ser şanoya zarokan ya kurdî jî hinek agahî par ve kirin. Li gor wî heta niha ji bilî wan şanoyek bi navê 'Teatra Zîv' çîroka 'Şengê û Pengê' û Şaredariya Bajarê Mezin a Amedê jî bi zazakî 'Pirê û Luvî' lîstine.
} 
Eger li gor teoriya performansê were gotin, tevna çîrokê tê guhertin. Ji aliyê din, ji ber ku bi awayekî înteraktîf 'çîrok' tê lîstin, dikare were gotin ku 'kontekst' jî di van mînakan de tê guhertin. Tiştekî din ê balkêş, di 'çîrok'ê de lîstikvan an jî derhêner hinek lîstikên zarokan ên gelêrî dixê nava 'çîroka' xwe ya li ser dikê û di wir de hem lîstikvan û hem jî temaşevan di nav 'çîrokê' de cih digirin. Yanî bi gotina Bilal Korkut, "temaşevan jî dibin lîstikvan û lîstikvan dibin temaşevan". ${ }^{25}$ Ev jî dide xuyakirin ku êdî çîrok ne bi rengê xwe yê 'gelêrî' li ser dikê ye, lê bi rengekî din, bi metineke 'sererastkirî'. Bi gotineke din êdî wek ku di vê mînakê de jî tê dîtin, metineke 'nû', di konteksteke 'nû' de û bi tevneke 'nû' careke din tê gotin. Ji van mînakan jî tê xuyakirin ku vegotinên gelêrî di nav civakê de bi şêweyeke din, bi 'vegotineke din' careke din xwe zindî dikin.

\section{ENCAM}

Di vegotinên gelêrî de ragihandina di navbera guhdarvan û vebêjer de tiştekî girîng tê dîtin. Bi guherînên di nav civakê de ev têkilî jî tê guhertin û ev yek jî rengekî nû didê vegotinên gelêrî.

Vegotinên gelêrî, ku binbeşeke girîng ya edebiyata gelêrî ye, di nav xebatên folklorê de cihekî sereke digirin. Ji destpêka xebatên folklorê heta îro jî vê mijarê bala gelek folklornasan kişandiye. Ji aliyekî ve berhevkirina wan û ji aliyê din ve jî nirxandinê cuda rê li ber nêrîn û teoriyên cuda vekiriye. Yek ji van teoriyan jî 'teoriya performansê' ye ku hêmanên folklorî -û bêhtir jî vegotinên gelêrî- di çarçoveya 'îcrakirin'ê de dinirxîne. Li gor vê teoriyê êdî divê hemanên folklorê di nav kontekst û tevnê de werin nirxandin.

Pêşketinên teknolojîk, guherînên di civakê de û derfetên nû rê li ber 'ji nû vegotin'a van hemanên edebiyata gelêrî vedikin. Hêmanên ku hatine berhevkirin êdî li ser dikên şanoyan, di televizyonan û di muzeyan de 'ji nû ve tên vegotin' û tên pêşkêş̧irin ku têkiliya vebêjer û guhdarvan an jî temaşevan ji binî ve diguhere. Ev yek jî tê wateya ku hêmanên folklorî ne tiştên 'kevnar' û 'cemidî' ne, lê diyardeyên zindî û guherbar ku li gor rewş û derfetên civakê, li gor pêwistiyên civakê xwe diguherinîn an jî 'ji nû ve tên vegotin'. Nimûneyên ku di gotarê de hatin dayîn jî vê yekê didin xuyakirin.

Her çiqasî hîna di destpêkê de be jî, ev yek ji bo hêmanên folklora kurdî jî dikare were gotin. Wek ji mînakên li jor hatine dayîn jî tê xuyakirin, bi guherînên di civakê û bi derfetên 'nû', vegotinên gelêrî yên kurdî jî careke din 'ji nû ve tên gotin'. Ji ber vê yekê jî nirxandina wan jî divê ne tenê li gor 'metn'ê, lê belê di heman demê de li gor kontekst û tevna 'nû', yanî bi gotineke din di çarçoveya 'teoriya performansê' de were kirin. Ev yek dê bêhtir rê li ber famkirina binyad û bikaranîna wan ya îroyîn ya vegotinên gelêrî veke.

\footnotetext{
25 Ji bo nirxandinek li ser heman lîstikê bnr. Derbarê çîrokê de: http://diyarname.com/article.php?Idx=2169 dîroka lênêrînê:19.01.2016
} 


\section{ÇAVKANî}

Aslan, F. (2011). İstanbul'da Bir Sene Birinci Ay Tandırbaşı Adlı Kitapta Yer Alan Masalın Performans Teoriye Göre İncelenmesi Üzerine Bir Deneme. Türk Dili Ve Edebiyatı Dergisi, 2011-1, 83-140.

Başaran, U. (2013). Atasözlerinin Kalıpsallı̆̆ Üzerine. Turkish Studies, 8/9, 757-770.

BaşGöz, İ. (1988). Masalın Anlatıcısı. Masal Araştırmaları/Folktale Studies I, İstanbul, 2529.

BaşGöz, İ. (2001). Sözlü Anlatımda Ara Söz: Türk Hikaye Anlatıcılarının Şahsi Değerlendirmelerine Ait Bir Durum İncelemesi (çev. Metin Ekici). Milli Folklor, Yıl: 13, Say1: 50, 86-104.

Ben-Amos, D. (1971). Toward a Definition of Folklore in Context. The Journal of American Folklore, vol. 84, no.331, 3-15.

Çobanoğlu, Ö. (1998). Sözlü Kompozisyon Teorisi ve Günümüz Halkbilim Çalışmalarındaki Yeri, folkloristik, Ankara.

Çobanoğlu, Ö. (2012). Halkbilimi Kuramları ve Araştırma Yöntemleri Tarihine Giriş, Ankara: Akçağ

Dorson, R. M.(ed.) (1972). Concepts of Folklore and Folklife Studies. Folklore and Folklife (ed.R.M.Dorson), The University of Chicago Press: Chicago \& London, pp.1-51.

Dorson, R. M. - THOMS, W. J. (1997). William John Thoms ve 'Folklore' Başlıklı Yazısı (çev. S. Cengiz). Milli Folklor, sayı. 36, 89-92.

Dundes, A. (1998). Doku, Metin ve Kontekst (çev. M. Ekici). Milli Folklor sayı:38, 106-119.

Ersoy, R. (2004). 'Performans Teori' Bağlamında Sözlü Kültür Ürünlerinin Müzelenmesi Sorunu Üzerine Bazı Görüş ve Düşünceler. Somut Olmayan Kültürel Mirasin Müzelenmesi Sempozyum Bildirileri (Yay.haz. M.Öcal Oğuz vd.), Ankara: Gazi Üniversitesi THBMER yay, 57-67.

Hamelınk, W. \& Barıs, H. (2014). Dengbêjs on borderlands: Borders and the State as Seen Through the Eyes of Kurdish Singer-poets, Kurdish Studies, Volume: 2, No: 1, 34 60. www.kurdishstudies.net

Karadağ, M. (2004). Türk Halk Edebiyatı Anlatı Türleri (4.bsk), Ürün yayınları: Ankara.

Keskin, N. (2015a). Tûr-Abdin'de Bir Kimlik ve Anlatım Biçimi: Mitırblar ve Mitrıplık. Folklor/Edebiyat, cilt: 21, sayt:84, (2015/4), 57-72.

Keskin, N. (2015b). Mitirb û Mitirbî: Nasname û Vegotin. Wêje û Rexne, 6, 109-120. 
Kızıl, H. \& Tanrıkulu, V. (2015). Berawirdkirina çîroka Hedlîlik Bedlîlik a bi Kurdî bi Gur û Heft Karikan a Birayên Grimm re. International Journal of Kurdish Studies 1 (2), 70 85 .

Magoulick, M. (2015). Fieldwork/Ethnography and Performance Theory, https://faculty.gcsu.edu/custom-website/mary-magoulick/performance.htm Dîroka lênêrînê: 09.11.2015.

Ong, W. J. (2003). Sözlü ve Yazılı Kültür. (3.bsm.). İstanbul: Metis Yayınları.

Özbudun, S. \& Şafak, B. \& Altuntek, S. N. (2007). Antropoloji: Kuramlar/Kuramcılar (2.bsk), Dipnot:Ankara

Örnek, S. V. (2000). Türk Halkbilimi (2.bsk). Kültür Bakanlığı:Ankara

Öztürkmen, A. (1998). Folklor ve Milliyetçilik. İstanbul: İletişim.

Pertev, R. (2015). Edebiyata Kurdî ya Gelêrî. Stenbol:Avesta.

Uzun, M. (1998). Dengbêjlerim, İstanbul: Gendaş Kültür

Mutlu, E. (1996). Kürt Müziği Üzerine. Kürt Müziği (Nezan, Izady, Tatsumura, Mutlu, Poche, Christensen, Komitas). İstanbul: Avesta, 53-64.

Yıldırım, K. \& Pertev, R. \& Aslan, M. (2013) Ji Destpêkê Heta Niha Folklora Kurdî. Mardin: Mardin Artuklu Üniversitesi Yayınları.

\section{MALPER:}

-http://diyarname.com/article.php?Idx=2169 -dîroka lênêrînê 19.01.2016

-http://zaroktv.com.tr/Kurmanci/Program/Heb-tune-b -dîroka lênêrînê ya dawî:19.01.2015

-http://www.sinemavesinema.com/adile-nasit-vefatinin-28-yilinda-sevenleri-tarafindan-anildic3237.html - dîroka lênêrînê: 20.12.2015

-https://tr.wikipedia.org/wiki/Adile Naşit -dîroka lênêrînê 20.12.2015

-http://www.kulturelmirasmuzesi.com/index.php -dîroka lênêrînê:15.11.2015

-http://turk_halkbilimi.gazi.edu.tr -dîroka lênêrînê:15.11.2015

-http://www.ankarakultur.gov.tr/servisler/kultur-ve-tabiat-varliklari/muzeler/somut-olmayankulturel-miras-muzesi -dîroka lênêrînê:15.11.2015

-http://mardintiyatro.org/festival-2015/ -dîroka lênêrînê: 20.12.2015

-http://mardintiyatro.org/wp-content/uploads/2015/11/MardinKatalog-2015-dijital.pdf-dîroka lênêrînê: 20.12.2015 
-http://www.counter-currents.com/2011/05/herders-theory-of-the-volksgeist/print/ -dîroka lênêrînê: 09.10.2015.

-http://www.unesco.org/culture/ich/en/what-is-intangible-heritage-00003 -dîroka lênêrînê ya dawî:11.12.2015.

-http://www.unesco.org/culture/ich/en/convention\#art2 - dîroka lênêrînê ya dawî:11.12.2015. 